\title{
Photoemission from Diamond and Fullerene Films for Advanced Accelerator Applications
}

\author{
P. Muggli, R. Brogle, S. Jou, H. J. Doerr, R. F. Bunshah, and C. Joshi, Fellow, IEEE
}

\begin{abstract}
The photoemission properties of thin diamond and fullerene films were investigated for advanced accelerator applications, using subpicosecond laser pulses at three different wavelengths $(650,325$, and $217 \mathrm{~nm})$. The quantum efficiency (QE) obtained at $217 \mathrm{~nm}$ with a boron-doped, $p$-type, (111) polycrystalline diamond film $\left(2.6 \cdot 10^{-4}\right)$ was only five times smaller than the QE obtained with a mirror polished copper sample $\left(1.3 \cdot 10^{-3}\right)$ but more than nine times larger than the QE obtained with a pure diamond film or with natural diamond monocrystals. Similar results were obtained for the two-photon electron yields at $325 \mathrm{~nm}$. The electron yields obtained with pure fullerene films were small and comparable to the ones observed with the pure diamond samples. With $650 \mathrm{~nm}$ pulses, the damage threshold of the (110) Type IIa natural diamond monocrystal $\left(9.38 \cdot 10^{4} \mu \mathrm{J} \mathrm{cm} \mathrm{cm}^{-2}\right)$, defined here as the fluence leading to an onset of ion emission, was 25 times larger than the damage threshold for a copper sample $\left(3.75 \cdot 10^{3} \mu \mathrm{J} \mathrm{cm}^{-2}\right)$. The damage threshold of the boron-doped sample at the same wavelength was two times larger than that of copper. Damage thresholds with 325 $\mathrm{nm}$ pulses were lower, and with $217 \mathrm{~nm}$ pulses ion emission was observed at all fluences probably attributed to ablation of surface hydrocarbon contaminants. Results show that high-quality highboron concentration diamond films could be a good candidate for high-RF electron guns.
\end{abstract}

\section{INTRODUCTION}

$\mathbf{R}$ ADIO frequency photoinjectors (RF guns) are commonly used to produce single high-energy (a few MeV) electron bunches or trains of electron bunches. In these devices, short ultraviolet (UV) laser pulses are incident on a photocathode to produce electrons by a one-photon photoelectric process. The electrons are born with a low energy $(<1 \mathrm{eV})$ and accelerated to $\mathrm{MeV}$ levels by the large electric field $(\approx 100 \mathrm{MV} / \mathrm{m})$ of the resonant RF structure. The choice of the photocathode material depends on the following factors: its quantum efficiency (QE) at the available UV wavelength, its prompt response to the laser excitation, its behavior in the high-electric fields of the $\mathrm{RF}$ structure (conductivity, surface roughness, etc.), its optical damage threshold at the given wavelength, and its ability to maintain these characteristics in the long term when exposed to the RF gun environment (change of chemical and/or physical

Manuscript received January 16, 1996; revised March 5, 1996. This work was supported by the U.S. Department of Energy Grant DE-FG03-91 ER12114 and DE-FG03-92-ER40727, by the U.S. Office of Naval Research Grant N0014-90-J-1952, and by the Fonds National Suisse de la Recherche Scientifique under Grant 8220-040 122

P. Muggli, R. Brogle, and C. Joshi are with the Department of Electrical Engineering, University of California, Los Angeles, CA 90024 USA (e-mail muggli@ee.ucla.edu).

S. Jou, H. J. Doerr, and R. F. Bunshah are with the Department of Materials Science and Engineering, University of California, Los Angeles, CA 90024 USA.

Publisher Item Identifier S 0093-3813(96)04230-0. surface properties). Existing RF guns use essentially two types of materials. The first type is metallic photocathodes (copper [1], magnesium [2], etc.) which are robust and prompt and have a relatively low work function $(\phi=3-5 \mathrm{eV})$, but their measured QE's are only in the $10^{-5}-10^{-3}$ range even at wavelengths as short as $213 \mathrm{~nm}$ [3]. The second type is alkali photocathodes [3] ( $\mathrm{CsI}, \mathrm{Cs}_{2} \mathrm{Te}$, alkali halides, or $\mathrm{Cs}_{3} \mathrm{Sb}, \mathrm{K}_{3} \mathrm{Sb}$, alkali antimonides) which exhibit a high QE $\left(10^{-2}-10^{-1}\right)$ but require ultra-high vacuum (better than $10^{-9}$ torr). These photocathodes have a $\mathrm{QE}$ that usually decreases over a short period of time (hours or days), and they need to be reconditioned or replaced periodically. However, in both cases the maximum charge obtained per pulse when placed in an RF gun is comparable, since the maximum charge is limited by space-charge effects. The issue of the promptness of the photoemission process resulting from femtosecond laser pulse illumination remains unaddressed, mainly due to the lack of methods available to measure femtosecond electron bunches. While many of the existing RF guns operate at low RF frequency (144 MHz, $1.3 \mathrm{GHz}$ or $2.8 \mathrm{GHz}$ ), a higher $\mathrm{RF}$ frequency would allow for higher electric fields and higher accelerating gradients $(\approx 250 \mathrm{MV} / \mathrm{m}$ peak [4]). A resonant cavity with a higher frequency would be smaller, and the laser spot size on the cathode would have to be decreased to preserve the electron optics characteristic of the structure. To obtain the same charge, the energy of the laser pulse would have to be kept constant (one-photon process), and the laser intensity incident on the cathode would increase with the square of the RF increase, leading to potential surface damage. Alternative materials suitable for photoemission in RF guns that have a high surface damage threshold are thus required. In this paper we investigate the photoemission properties of thin diamond and fullerene films using subpicosecond laser pulses at three different wavelengths $(650,325$, and $217 \mathrm{~nm})$ for such advanced accelerator applications.

Diamond has many extreme characteristics (Table I). When pure, it is an insulator and has the lowest electrical conductivity of all materials, 22 orders of magnitude lower than that of copper. It is the hardest of all materials, has a heat conductivity 2.5 to 5 times higher than copper, and a thermal expansion coefficient comparable to that of Invar. It is a large bandgap insulator $(5.45 \mathrm{eV})$, but its unreconstructed (111) surface exhibits negative electron affinity (NEA). Hydrogen plays a major role in the production of artificial diamond. The presence of hydrogen on the surface of (111) Type Ilb natural diamond has been shown to be the cause of the NEA exhibited by the surface [5]. Exposing the diamond surface to an argon 
TABLE I

Some Physical Properties of Natural Diamond and Their Corresponding VAlues for RELATED MATERIALS. (COMPILED FROM THE CRC HANDBOOK OF Chemistry and Physics.) Note: All Properties at RoOM TeMPERature

\begin{tabular}{|c|c|c|c|}
\hline PropertylValue & Diamond & \multicolumn{2}{|c|}{ Other Material } \\
\hline Lattice Constant (cubic) $(\dot{A})$ & 3.57 & 3.62 & $\mathrm{Cu}$ \\
\hline Work Function $(11 \mathrm{l})(\mathrm{eV})$ & $5.5^{(6)}$ & 4.6 & $\mathrm{Cu}$ \\
\hline Band $\operatorname{Gap}(e V)$ & 5,45 & 1.35 & GaAs \\
\hline Electron Mobility $\left(\mathrm{cm}^{2} V^{-1} \mathrm{~s}^{-1}\right)$ & 2000 & 400 & GaAs \\
\hline Hole Mobility $\left(\mathrm{cm}^{2} V^{\cdot l} \mathrm{~s}^{-1}\right)$ & 1800 & 8500 & GaAs \\
\hline Resistivity $(\Omega m)$ & $1.0 \cdot 10^{14}$ & $1.7 \cdot 10^{-8}$ & $\mathrm{Cu}$ \\
\hline Electrical Breakdown $\left(-10^{6} \mathrm{~V} \mathrm{~cm}^{-1}\right)$ & 10 & 5 & $S i$ \\
\hline \multirow[t]{3}{*}{ Thermal Conductivity $\left(\mathrm{W} \mathrm{m}^{-1} \mathrm{~K}^{-1}\right)$} & 990 (type I) & 401 & $\mathrm{Cu}$ \\
\hline & 2320 (type IIa) & 150 & Si \\
\hline & 1360 (type IItb) & 46 & GaAs \\
\hline Thermal Exp. Coeff. $\left(\cdot 10^{6} \mathrm{~K}^{-1}\right)$ & 0.8 & 0.64 & Invar \\
\hline Hardness ( $\mathrm{kg} \mathrm{mm}^{-2}$, Knoop Value) & 7000 & 163 & $\mathrm{Cu}$ \\
\hline
\end{tabular}

plasma is an effective way to clean the surface of its hydrogen and to remove the NEA. The diamond conduction band lies only $0.35 \mathrm{eV}$ below the vacuum level [6]. Diamond has been used as a thermionic emitter and as a cold cathode [7]. Field emission has been obtained from polycrystalline chemical vapor deposited (CVD) diamond films [8] by applying less than $3 \mathrm{MV} \mathrm{m} \mathrm{m}^{-1}$ which is three orders of magnitude less than the field required for Fowler-Nordheim emission from metals. Diamond can be $n$ - or $p$-type doped [9], and as a semiconductor it exhibits high electron and hole mobility. Its surface is insensitive to exposure to oxygen, water, or air, and unlike other thermionic emitters does not exhibit an (ampere . hour $=$ constant) emission law [10]. Natural semiconductive diamond (blue, Type IIb) exists because of incorporated boron [11] and not aluminum, as previously assumed. It exhibits $p$-type behavior with a resistivity of $10-1000 \Omega \mathrm{cm}$. The acceptor level of boron-doped diamond is $0.37 \mathrm{eV}$ above the valence band. Type Ia natural diamond contains up to $0.1 \%$ nitrogen in aggregate or plate form. Its resistivity is $10^{16} \Omega \mathrm{cm}$, and the donor level is $1.7 \mathrm{eV}$ below the bottom of the conduction band which is too large for its use as an $n$-type semiconductor. Diamond film growth has been obtained on different substrates such as $\mathrm{Si}, \mathrm{Mo}$, and $\mathrm{Cu}$ [12].

Fullerenes are new allotropic forms of elemental carbon whose existence and stability [13] $\left(\mathrm{C}_{60}\right.$ and $\left.\mathrm{C}_{70}\right)$ and production in macroscopic quantities [14] have been reported only recently. In the $\mathrm{C}_{60}$ molecule the 60 carbon atoms are arranged on the vertices of a $7-\AA$ diameter, hollow truncated icosahedron (soccer ball or geodesic structure) having 32 faces, 12 of which are pentagons and 20 hexagons. Higher stable fullerenes $\left(\mathrm{C}_{2 n}, n>30\right.$ such as $\mathrm{C}_{70}, \mathrm{C}_{84}, \mathrm{C}_{76}, \mathrm{C}_{78}$, etc. $)$ are all composed of three connected networks of $\mathrm{C}$ atoms arranged in 12 pentagons and a varying number of hexagons to form spheroidal molecules. The fullerenes are extracted from carbon soot by solution in toluene and evaporation of the toluene. The $\mathrm{C}_{60}$ can be separated from other fullerenes by sublimation. The $\mathrm{C}_{60}$ crystallizes on a face-centered-cubic ( $\mathrm{fcc}$ ) lattice to form a direct bandgap semiconductor with a roughly $1.7-\mathrm{eV}$ bandgap [15]. The ionization potential of $\mathrm{C}_{60}$ gas phase molecule [16] is $7.6 \pm 0.2 \mathrm{eV}$. The work function of $\mathrm{C}_{60}$ deposited on $\mathrm{Si}(100)$ is $6.8 \mathrm{eV}$ [17]. Alkali metal incorporation into the $\mathrm{C}_{60}$ lattice (fullerite) has produced conducting fullerides [18], and superconductivity has been observed [19] at $18 \mathrm{~K}$ with $\mathrm{K}_{x} \mathrm{C}_{60}$.

In previous works, photoelectron yield versus UV wavelength and photoemission spectra have been used to study the band structure of diamond [6] and fullerene [17]. This paper reports on the photoemission characteristics of diamond and fullerene films used as electron emitters for advanced accelerator applications. Relatively high QE's $\left(2.6 \cdot 10^{-6}\right.$, only five times smaller than that of copper) have been measured with $5.73 \mathrm{eV}$ photons incident on a boron-doped diamond film. Section II gives a brief description of the photoemission processes. Sections III and IV describe the preparation of the diamond and fullerene films. Section $\mathrm{V}$ describes the experimental setup. The photoemission results are presented in Section VI, the damage results in Section VII, and they are summarized and discussed in Section VIII.

\section{Photoemission Processes}

One-photon [20] (photoelectric effect) and multiphoton photoemission processes from metals [21], [22], semiconductors [23], and insulators [24] have been extensively studied in the past. For multiphoton photoemission to be observed, the incident light intensity has to be large enough so that electrons can absorb $n$ number of photons consecutively to gain enough energy to overcome the material work potential barrier. The signature of such $n$-photon processes is the $n$th power dependency of the emitted current density on the incident light intensity. The total current density $J$ generated by a light beam of intensity $I$ and frequency $\nu$, incident upon a surface of work function $\phi$, is given by the generalization of the Fowler [25] and DuBridge [26] theory

$$
J=\sum_{n=0}^{\infty} J_{n}
$$

where

$$
J_{n}=a_{n} A\left(\frac{e}{h \nu}\right)^{n}(1-R)^{n} I^{n} T_{e}^{2} F\left(\frac{n h \nu-e \phi}{k_{B} T_{e}^{2}}\right) .
$$

$n$ is the order of the $n$-photon process, $A=120 \mathrm{~A} \mathrm{~cm}^{-2}$ $\mathrm{K}^{-2}$ is the theoretical Richardson coefficient for a clean metal, $e$ is the electron charge, $h$ is the Planck constant, $k_{B}$ is the Boltzmann constant, and $R$ is the intensity reflection coefficient of the surface for the light of frequency $\nu$. The $a_{n}$ coefficient is a material dependent constant that, in a simplified model, includes the probability for an electron to absorb a photon of energy $h \nu$ and the probability for an electron to go through the surface. In the case of a metal, the Fowler function $F(x)$ is proportional to the number of electrons available for each process, according to their Fermi-Dirac distribution function in the conduction band of the metal at temperature $T_{e}$. In absence of thermal effects ( $T_{e} \approx$ room temperature), the order of the dominant $n$-photon process is given by the integer $n$ such that

$$
\frac{e \phi}{h \nu} \leq n<1+\frac{e \phi}{h \nu} .
$$


Expression (2) with $n=0$ yields the thermionic current density.

The case of semiconductors is slightly different than that of metals. The work function $\phi$ is still defined as the energy difference between the vacuum level and the Fermi level. The electron affinity $\chi$ is defined as the energy difference between the lowest conduction band state and the vacuum level. For a semiconductor, the value of $\chi$ appears more characteristic of the surface than is the value of $\phi$. In the absence of surface states, changing the semiconductor bulk from $p$-type (Fermi level near the top of the valence band) to $n$-type (Fermi level near the bottom of the conduction band) would decrease the work function by an amount almost equal to the bandgap. However, if the spectrum of the state levels is dense in the gap region, and only partly filled, then attempts to change the Fermi level at the surface will result in filling or emptying the surface states. The net charge residing at the surface will change, a depletion or accumulation layer will form near the surface, and the Fermi level at the surface will only slightly change. The surface Fermi level is then "pinned" by surface states, and the work function is not greatly influenced by changes in the bulk Fermi level arising from the doping of the semiconductor. Enhancement of the photoelectron yield of a semiconductor surface could thus be obtained by $p$-doping an intrinsic semiconductor to decrease its electron affinity $\chi$ [27]. In the case where the value of $\chi$ is negative, the surface is said to exhibit NEA. In the following paragraphs, the term "work function," i.e., the energy difference between the vacuum level and the Fermi level, will be used in place of the term "photoelectric threshold," i.e., the difference between the vacuum level and the last occupied level. The value of these two parameters are equal for a clean metal but differ for a semiconductor.

For laser pulses with fixed full width at half-maximum (FWHM) duration $\sigma_{t}$ and full width spot size area $S_{r}$, the total emitted charge $Q_{n}$

$$
Q_{n}=\int d t \int d s J_{n}=\sigma_{t} S_{r} J_{n}
$$

versus the pulse total absorbed energy $E$

$$
E=\int d t \int d s I=\sigma_{t} S_{r} I
$$

can be written as [from (2)]

$$
Q_{n}=b_{n} E^{n} \text {. }
$$

The order $n$ is obtained from the slope $S_{n}$ of $Q$ versus $E$ on a $\log -\log$ plot and the value of the $b_{n}$ coefficient from the measurement of $Q$ versus $E$, both in the $Q_{n} \propto E^{n}$ regime, i.e., in the space-charge free regime (Section VI-A). The electron yield $b_{n}$ is obtained from the power fit

$$
Q_{n}=b_{n} E^{S_{n}} \text {. }
$$

The QE for a one-photon process is given by

$$
\begin{aligned}
\mathrm{QE} & =b_{1}\left[\mathrm{CJ}^{-1}\right] \cdot E_{\text {photon }}[\mathrm{eV}] \\
& =10^{-6} \cdot b_{1}\left[\mathrm{pC} \mu \mathrm{J}^{-1}\right] \cdot E_{\text {photon }}[\mathrm{eV}]
\end{aligned}
$$

Note that it has been assumed in (4) that the electron emission is prompt and thus that the current density follows (2). In the case of a nonprompt $n$-photon emission process, the total emitted charge (measured in this experiment) would remain the same if the current density is integrated over a long enough time $\left(\gg \sigma_{t}\right)$. The $b_{n}$ coefficients deduced from the experimental curves also include effects of the real surface, such as presence of oxide or contaminants, that could influence the electron yields.

One of the requirements for advanced accelerator applications is for the cathode to produce subpicosecond electron bunches. Only photocathodes illuminated by short laser pulses seem to be able to fulfill that requirement. There is not yet any conclusive measurement of the electron bunch length produced by such cathodes, and the promptness of the electron emission remains an open issue. In the case of metallic photocathodes, more than $98 \%$ of the photons transmitted through the surface are absorbed within four skin depths $(\delta)$ for the incident light wavelength. The conduction band electrons that absorb a photon have a maximum energy above the Fermi level equal to that of the photon, and only those with an energy above that of the vacuum level $(e \phi)$ will eventually be emitted. The electrons that encounter electron-electron collisions lose most of their energy [28] and will not be emitted. The transit time of $4.6 \mathrm{eV}$ electrons (those likely to be emitted in the case of copper) from four skin depths deep inside the metal ( $\delta=$ $102 \mathrm{~nm}$ for $217 \mathrm{~nm}$ light), and the surface is of the order of $34 \mathrm{fs}$. Based on these arguments, the photoemission process from metallic cathodes can be considered as prompt for laser pulses longer than $100 \mathrm{fs}$. The promptness of photoemission for transparent materials is a more complex issue. Dopeddiamond is a semiconductor with a relatively low conductivity. It is transparent to visible light and absorbs UV light with photon energy higher than its bandgap $(5.45 \mathrm{eV})$. The relevant parameter for the emission promptness is the mean free path of the excited electrons in the visible range, and the penetration depth of the light in the above bandgap range. The excited electrons' mean free path is expected to be short since the boron-doped diamond conductivity is low. Experiments are in progress at UCLA to determine the excited electron mean free path in metals and in transparent materials.

\section{DIAMOND FILMS PREPARATION}

Diamond films are grown by various chemical vapor deposition (CVD) techniques using fluid-hydrogen mixtures as a feed material [29]-[31]. The films used in this experiment were obtained by a new process [32]: the plasma enhanced chemical transport (PECT). Carbon was transported by a $400-500 \mathrm{~W}$ dc hydrogen plasma from a graphite cathode and deposited as diamond on a (100) silicon substrate placed on an anode. The substrate temperature was about $850^{\circ} \mathrm{C}$. The hydrogen was kept static in the plasma chamber at a pressure of 100 torr. Keeping the hydrogen static rather than letting it flow reduced the amount of amorphous carbon in the thin film [32]. Diamond nucleation was low on virgin silicon surfaces $\left(10^{4}-10^{6} \mathrm{~cm}^{-2}\right)$. The silicon substrates were polished with $1-2 \mu \mathrm{m}$ diamond paste and cleaned with deionized water 


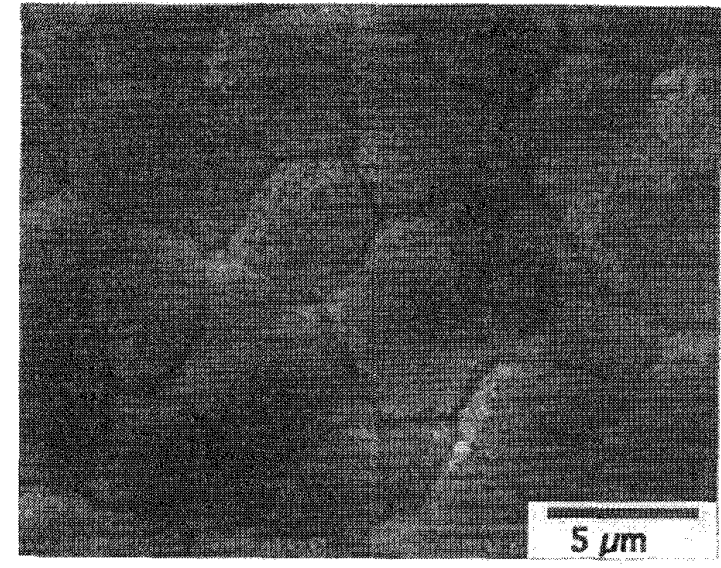

Fig. 1. SEM picture of the cauliffower diamond sample surface.

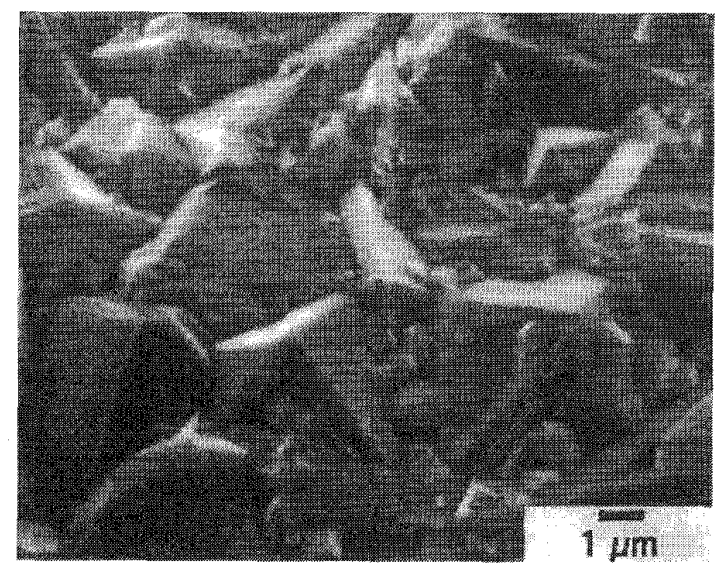

Fig. 2. SEM picture of the well-oriented diamond sample surface.

before the deposition to increase the nucleation to $10^{6}-10^{8}$ $\mathrm{cm}^{-2}$. The observed diamond growth was $1 \mu \mathrm{m} / \mathrm{h}$. The films were analyzed by scanning electron microscopy (SEM), microRaman spectroscopy, and X-ray diffraction (XRD). Surface roughness was measured by a Sloan Dektak II profilometer with an horizontal resolution of $0.025 \mu \mathrm{m}$ and a vertical resolution of $1 \AA$. A cauliflower (Fig. 1) or a well-oriented (Fig. 2) diamond structure could be obtained by changing the PECT parameters [32]. The peak at $1334 \mathrm{~cm}^{-1}$ in the Ramanshifted spectrum of the well-oriented diamond film, arising from the vibration of the crystal lattice of ${ }^{12} \mathrm{C}$-diamond, was intense and dominated the small and broad peak at $1550 \mathrm{~cm}^{-1}$, characteristic of amorphous carbon (graphite-like) commonly designated $s p^{2}$. The XRD spectrum showed a predominant (111) peaks with very small (220) and (311) peaks. The same spectra for the cauliflower film showed as much diamond film quality.

Carbon is an element of the fourth group (IV-A) in the periodic table of elements, as is silicon, and diamond and silicon have the same crystal structure. Each carbon atom of the diamond has four neighbors with which it forms covalent bonds in a tetrahedral configuration. Diamond can be doped with elements of the third group (trivalent) such as boron to become a $p$-type semiconductor or with elements of the
TABLE II

Characteristics of the Diamond Samples. The Surface

ROUGHNESS IS MEASURED OVER A $25 \mu \mathrm{m}$ (MACRO) AND $2 \mu \mathrm{m}$ (Micro) Scale. The Resistivity of the Doped Sample Is Given

\begin{tabular}{|c|c|c|c|c|c|}
\hline Sample & $\begin{array}{l}\text { Thickness } \\
{[\mu \mathrm{m}]}\end{array}$ & $\begin{array}{l}\text { Roughness } \\
{[\AA]}\end{array}$ & Dopanr & Type & Remarks \\
\hline Cauliflower & 1 & $\begin{array}{r}6000 \text { (macro) } \\
40 \text { (micro) }\end{array}$ & $\cdots$ & $I$ & \\
\hline Well oriented & 2 & $\begin{array}{r}5000 \text { (macro) } \\
4 \text { (micro) }\end{array}$ &.-- & $I$ & \\
\hline B-doped & 4 & $\begin{array}{r}1000 \text { (macro) } \\
8 \text { (micro) }\end{array}$ & boron & $p^{*}$ & $4.3 \cdot 10^{-2} \Omega \mathrm{cm}$ \\
\hline
\end{tabular}

* The boron-doped diamond films were tested $p$-type by observing polarity in hot-probe and rectify junction measurement, and exhibited a well-oriented structure.

fifth group (pentavalent) such as phosphorous to become an $n$-type semiconductor. Phosphorus (group V) is expected to be a substitutional dopant, i.e., replace a carbon atom in diamond lattice. Other materials have been theoretically predicted as possible $n$-type dopants in synthetic diamond. Lithium and sodium (group I) are expected to be interstitial dopants, i.e., fill in interstitial sites in the diamond. The donor level of these $n$ type dopants is predicted to lie between 0.1 and $0.3 \mathrm{eV}$ below the bottom of the conduction band.

An additional doping apparatus was included in the PECT for dopant incorporation during the diamond growth. High dopant concentration was achieved by inserting the solid dopant into the plasma zone above the substrate surface. The dopant which was placed inside a tungsten coil was indirectly heated up by the hydrogen plasma, and the dopant vapor diffused to the substrate surface and codeposited with diamond. Boric anhydride (Purified, J. T. Baker Chemical Co.) was used for boron doping. Characteristics of the diamond samples are given in Table II. The boron-doped diamond film was tested $p$-type by observing polarity in hot-probe and rectifying junction measurement. The resistivity of the doped sample was measured with a four-points probe. The doping concentration of the boron-doped film was $8 \cdot 10^{19} \mathrm{~cm}^{-3}$ as measured by secondary ion mass spectroscopy (SIMS). The surface structure of both doped films was well oriented, predominantly (111), i.e., the doping did not alter the surface morphology of the film.

\section{Fullerene Films Preparation}

Fullerene powder, containing more than $95 \%$ of $\mathrm{C}_{60}$ and the remaining of $\mathrm{C}_{70}$ and higher fullerene, was extracted from the soot produced by resistive heating of graphite. This fullerene powder was evaporated from an alumina crucible which was heated by a tantalum wire to a temperature between 450 and $500^{\circ} \mathrm{C}$. Two fullerene films were prepared from a $\mathrm{W}$ boat evaporator in vacuum for the photoemission study. The first fullerene sample was deposited at $720 \AA / \mathrm{h}$ for $6.5 \mathrm{~h}$ onto a silicon (100) substrate at $100^{\circ} \mathrm{C}$ at a background vacuum pressure of $8 \cdot 10^{-6}$ torr. The second sample was deposited by passing fullerene vapor through an Ar plasma at $2 \cdot 10^{-2}$ torr and collected on a silicon $(100)$ substrate at $170^{\circ} \mathrm{C}$. The 


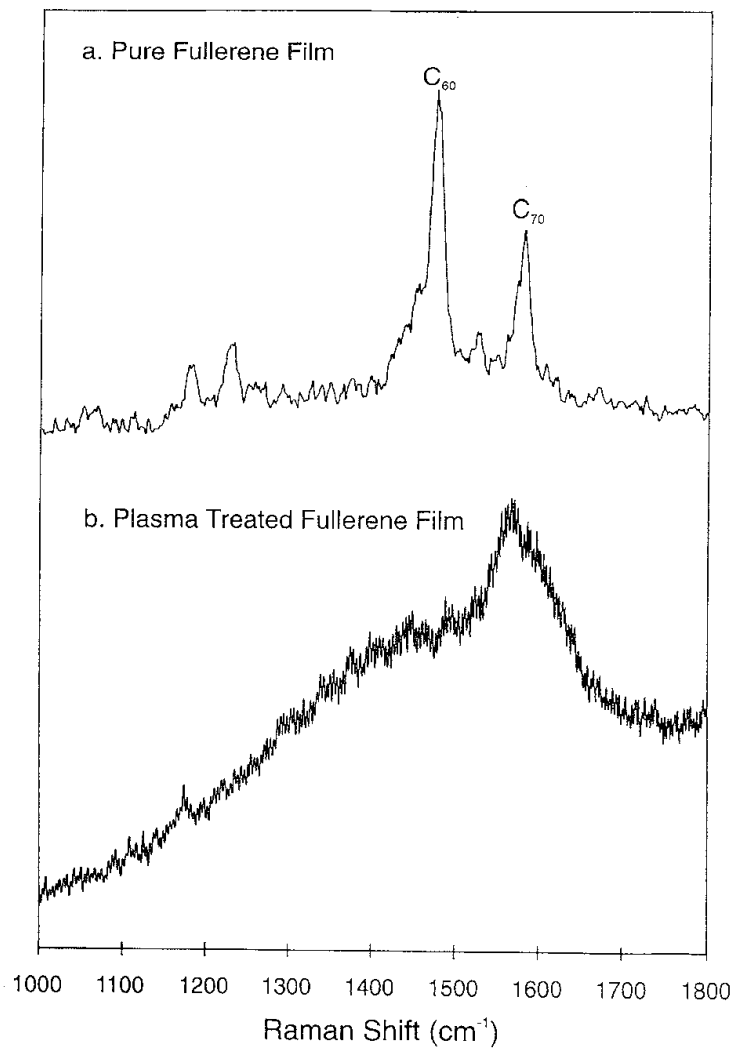

Fig. 3. Raman spectra for (a) the pure fullerene and (b) the argon treated fullerene sample. The peak at $1470 \mathrm{~cm}^{-1}$ is characteristic of $\mathrm{C}_{60}$ and peaks at $1570,1230,1186$, and $1060 \mathrm{~cm}^{-1}$ are characteristic of $\mathrm{C}_{70}$.

Ar plasma was generated between a tungsten filament and a graphite anode with $20 \mathrm{~W}$ dc power. The film was deposited at $1000 \AA / \mathrm{h}$ for $2 \mathrm{~h}$.

Fig. 3 shows the Raman spectra of these two fullerene films. The spectrum of the pure fullerene sample [Fig. 3(a)] is a combination of $\mathrm{C}_{60}$ showing a distinct peak at $1470 \mathrm{~cm}^{-1}$, and of $\mathrm{C}_{70}$ showing peaks at $1560,1230,1186$, and $1060 \mathrm{~cm}^{-1}$. The fullerene film prepared with the Ar plasma excitation [Fig. 3(b)] exhibits the Raman peak of the $C_{70}$ at $1560 \mathrm{~cm}^{-1}$ distinct features between 1100 and $1200 \mathrm{~cm}^{-1}$. It indicated that the $\mathrm{C}_{60}$ and $\mathrm{C}_{70}$ molecules retained their structure in the fullerene film. The microstructure of the Ar plasma-deposited fullerene changed, and it is very likely that the bonding between each fullerene molecule, i.e., intermolecular bonding, was changed by the presence of Ar during the deposition process. The plain fullerene film dissolved in hot toluene, indicating that only Van der Waals bonding were present in the solid form. However, the Ar plasma-deposited fullerene film was insoluble in hot toluene, indicating that the fullerene molecules were chemically bonded.

\section{EXPERIMENTAL SETUP}

An ultrafast dye laser is synchronously pumped by a modelocked, frequency doubled Nd:YAG laser to produce $2.5 \mathrm{~nJ}$, $200 \mathrm{fs}, 650 \mathrm{~nm}$ (red, $h \nu=1.91 \mathrm{eV}$ ) pulses at a rate of $76 \mathrm{MHz}$. A small fraction of the remaining infrared beam

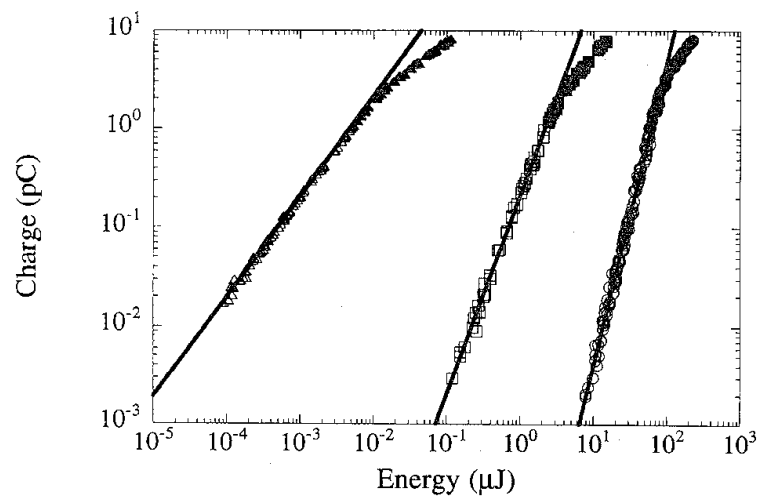

Fig. 4. Electron charge emitted by the mirror polished copper $(\phi=4.6 \mathrm{eV})$ illuminated at normal incidence. The measured slopes $S_{n}$ ( $n$-photon order), and the corresponding $b_{n}$ 's from (6), obtained through power fits (straight lines) below the space-charge regime $(Q<1 \mathrm{pC}$, open symbols), are given in Table III for the three wavelengths; circles: $h \nu=1.91$; squares: $h \nu=$ 3.82; triangles: $h \nu=5.73 \mathrm{eV}$. At higher charge values $(Q>1 \mathrm{pC}$, filled symbols), the electron emission becomes space-charge limited.

from the Nd:YAG laser is amplified in a $5-\mathrm{Hz}$ repetitionrate regenerative amplifier. It is frequency doubled to pump a dye amplifier that amplifies the red pulses to $2 \mathrm{~mJ}$ with a pulse broadening factor of 1.3-2.0, depending on the pumping fluence. The red pulse is split by a $50 \%$ beam splitter; onehalf is sent through the red delay line, and the other half is frequency doubled (UV, $325 \mathrm{~nm} ; h \nu=3.82 \mathrm{eV}$ ) in a Type I KDP crystal and sent through the UV delay line. A BG3 filter is placed after the doubling crystal to eliminate the remaining red energy. The red and the UV $p$-polarized pulses can be combined with a dichroic mirror, overlapped in time, and collinearly sent to a $0.5 \mathrm{~mm}$ Type I BBO mixing crystal to produce a UV $s$-polarized pulse at $217 \mathrm{~nm}(\mathrm{h \nu}=$ $5.73 \mathrm{eV}$ ). The $217 \mathrm{~nm}$ pulse is separated from the two others by reflection on four $45^{\circ}$-incidence mirrors coated for 217 $\mathrm{nm}$. Since in this experiment the electron yields for different $n$-photon processes are so different (see Fig. 4), the small fraction $(<0.5 \mu \mathrm{J})$ of the energy of the 650 and $325 \mathrm{~nm}$ pulses that reaches the samples does not contribute to the electron yield measurements. The spot area on the sample was $S_{r}=0.12 \mathrm{~cm}^{2}$ full width at full maximum (FWFM), and the length of the red pulse measured by autocorrelation was $\sigma_{t, 650}=700 \mathrm{fs}$ (FWHM). The temporal width of the $325 \mathrm{~nm}$ UV pulse measured by crosscorrelation with the red pulse in the mixing crystal was $\sigma_{t, 325}=520 \mathrm{fs}$. The shotto-shot energy of the pulses was monitored by calibrated photodiodes placed behind delay line mirrors or behind one of the wavelength separation mirrors. The temporal width and spot size of the pulses were assumed not to vary from shot to shot for a given set of measurements. The $650 \mathrm{~nm}$ pulse had an average intensity of $1.19 \mathrm{GW} \mathrm{cm}^{-2}$ at a $100 \mu \mathrm{J}$ energy, and the $325 \mathrm{~nm}$ pulse had an average intensity of 16.7 MW $\mathrm{cm}^{-2}$ at a $1 \mu \mathrm{J}$ energy. The pulsewidth of the $217 \mathrm{~nm}$ pulse was not measured in this experiment, but illumination of the samples with pulses at that wavelength yielded only one-photon processes that depend on the pulse energy and not on the pulse intensity [see (2)-(6)]. The intensity of the 217 $\mathrm{nm}$ pulse was estimated to be comparable to the $325 \mathrm{~nm}$ pulse 
TABLE III

Measured Slopes $S_{n}$ and Electron Yields $b_{n}$ with a Mirror Polished Copper SAMple $(\lambda / 20$ aT: $10.6 \mu \mathrm{m})$ and with the Copper Sample Holder (Average Value) with a Machine Finish Surface

\begin{tabular}{|c|c|c|c|c|c|c|}
\hline \multirow[b]{2}{*}{ Sample } & \multicolumn{2}{|c|}{$h v=5.73 \mathrm{eV}$} & \multicolumn{2}{|c|}{$h v=3.82 \mathrm{eV}$} & \multicolumn{2}{|c|}{$h v=1.91 \mathrm{eV}$} \\
\hline & $S_{1}$ & $\begin{array}{c}b_{\prime} \\
\left\{p C \mu \mu^{\prime \prime}\right]\end{array}$ & $S_{2}$ & $\begin{array}{c}b_{2} \cdot 10^{3} \\
{\left[p C \mu r^{2}\right]}\end{array}$ & $S_{3}$ & $\begin{array}{r}b_{3} \cdot 10^{6} \\
{\left[p C \mu J^{3}\right]} \\
\end{array}$ \\
\hline Copper mirror & 1.02 & 232 & 2.02 & 210 & 3.08 & 323 \\
\hline Copper holder & 1.01 & 275 & 2.03 & 261 & 3.70 & 392 \\
\hline
\end{tabular}

intensity for the same energy. A computer acquired the data at a $1 / 2 \mathrm{~Hz}$ rate. No averaging was performed; each point on the figures corresponds to an actual laser shot. The photocathode arrangement consisted of a copper holder that accommodates two samples and that was grounded through a 1-M $\Omega$ load resistor and of a hollow anode, placed at a distance of 3.0 $\mathrm{mm}$ away from the cathode and biased to a positive potential $(+5 \mathrm{kV})$. The samples were illuminated at normal incidence. The total time-integrated charge emitted by the photocathode was measured by using a charge sensitive preamplifier with an internal capacitance of $1 \mathrm{pF}$, placed in parallel with the 1-M $\Omega$ load resistor. Electrical contact between the diamond film and the ground was achieved through the silicon substrate $(r=$ $0.2-25 \Omega \mathrm{cm}$ ) and through two wires that held the samples in their resting cup.

\section{EXPERIMENTAL RESULTS}

\section{A. Copper}

Fig. 4 shows the electron charge emitted by a mirror polished $(\lambda / 20$ at $10.6 \mu \mathrm{m})$ copper sample $(\phi=4.6 \mathrm{eV})$ illuminated by the three different wavelengths available in this experiment. At low charge $(Q<1 \mathrm{pC})$, the charge versus incident energy follows a $Q_{n} \propto E^{n}$ dependency, and the measured slopes on the $\log -\log$ plot $S_{n}$ of 3.03, 2.01, and 0.99 clearly indicate three-, two-, and one-photon processes expected at the corresponding wavelengths $(650 \mathrm{~nm}, h \nu=$ $1.91 \mathrm{eV} ; 325 \mathrm{~nm}, h \nu=3.82 \mathrm{eV}$; and $217 \mathrm{~nm}, h \nu=5.73$ $\mathrm{eV})$. The electron yields of the samples $\left(b_{n}\right.$ in $(6)$, measured in $\mathrm{pC} \mu \mathrm{J}^{-n}$ for an $n$-photon process) were obtained from the power fit of these curves and are given in Table III. At higher charge $(Q>1 \mathrm{pC})$, the curves bend because of space-charge effects near the cathode surface. The space-charge effects could be shifted to a higher charge value by increasing the voltage applied between the cathode and the anode. In this experiment the electric field at the cathode surface was around $1.6 \mathrm{MV} \mathrm{m} \mathrm{m}^{-1}(5 \mathrm{kV}$ over $3 \mathrm{~mm})$ and is expected not to cause any observable lowering of the sample work function $\phi$ by Schottky effect [33] $\left(\Delta \phi_{\text {Schottky }}=0.05 \mathrm{eV}\right)$. Higher QE's are observed in RF guns because of the very high RF electric fields $\left(100 \mathrm{MV} \mathrm{m}^{-1}, \Delta \phi_{\text {Schottky }}=0.35 \mathrm{eV}\right)$.

The observed QE for the one-photon process on copper at $217 \mathrm{~nm}$ is 1.3 to $1.6 \cdot 10^{-3}$, compared to a one-photon QE of about $1.0 \cdot 10^{-5}$ observed at $266 \mathrm{~nm}$ under the same conditions [34]. Note that the ratio of these two QE's $(130-160)$ is in very
TABLE IV

The Order $n$ OF the $n$-Photon Process Deduced from THE Measurement of the Slope $S_{n}$ of the Charge Versus Energy Curves on the LoG-Log Plot Gives Limited Information About the Value of the Work Function $\phi$ of a Given Sample

\begin{tabular}{llr}
$h v(\mathrm{eV})$ & $n$ & Value of $\phi(\mathrm{eV})$ \\
\hline & & \\
& & \\
3.91 & 3 & $3.82<\phi<7.84$ \\
5.73 & 2 & $3.82<\phi<7.84$ \\
& 1 & $\phi<5.73$ \\
\hline
\end{tabular}

TABLE V

Measured Slopes $S_{n}$ AND Electron YieldS $b_{n}$ WITH the Boron $p$ - $(r=$ $11.0-25.0 \Omega \mathrm{cm})$ AND THE PHOSPHOROUS $n$-DOPED $(r=0.2-0.8 \Omega \mathrm{cm})(100)$ Sllicon Substrates Used for the Diamond and Fullerene Thin Films

\begin{tabular}{|c|c|c|c|c|c|c|}
\hline \multirow[b]{2}{*}{ Sample } & \multicolumn{2}{|c|}{$h v=5.73 \mathrm{eV}$} & \multicolumn{2}{|c|}{$h v=3.82 \mathrm{eV}$} & \multicolumn{2}{|c|}{$h v=1.91 \mathrm{eV}$} \\
\hline & $S_{i}$ & $\begin{array}{c}b_{l} \\
{\left[p C \mu J^{2}\right]} \\
\end{array}$ & $S_{2}$ & $\begin{array}{c}b_{2} \cdot 10^{3} \\
{\left[p c \mu \mu V^{-2}\right]} \\
\end{array}$ & $S_{3}$ & $\begin{array}{c}b_{3} \cdot 10^{6} \\
{\left[p C \mu N^{-3}\right]} \\
\end{array}$ \\
\hline n-doped Si & 1.02 & 3.75 & 2.12 & 1.95 & 3.77 & $86 \cdot 10^{-6}$ \\
\hline$p$-doped Si & 1.00 & 3.28 & 2.11 & 1.42 & 3.70 & $80 \cdot 10^{-6}$ \\
\hline
\end{tabular}

good agreement with the ratio expected from (2) (136.5)

$$
\frac{\mathrm{QE}_{217}}{\mathrm{QE}_{266}} \propto \frac{\left(1-R_{217}\right)}{\left(1-R_{266}\right)} \frac{F_{217}}{F_{266}}
$$

assuming that the $A$ and $a_{1}$ coefficients remain the same at 266 and $217 \mathrm{~nm}$ and assuming that the electron temperature $T_{e}$ remains equal to the room temperature. In (9), $R$ and $F$ are the reflection coefficients, and the Fowler function [25] at the two wavelengths: $R_{217}\left(45^{\circ}-s\right)=0.49, R_{266}\left(45^{\circ}-s\right)=$ $0.45, F_{217}=1003.8, F_{266}=6.8$. The QE measured at 266 $\mathrm{nm}$ is in good agreement with the value $\mathrm{QE}=0.84 \cdot 10^{-5}$ at $263 \mathrm{~nm}$ reported in [35] but is lower than the value $\mathrm{QE}=14.7 \cdot 10^{-5}$ at $266 \mathrm{~nm}$ reported in [36]. The $\mathrm{QE}$ measured at $217 \mathrm{~nm}$ is in good agreement with the value $\mathrm{QE}=70 \cdot 10^{-5}$ at 211 reported in [37] but is higher than the value $\mathrm{QE}=28.6 \cdot 10^{-5}$ at $211 \mathrm{~nm}$ reported in [35].

\section{B. Other Photoemitters}

The work function $\phi$ of the samples was not measured in this experiment. The measurement of the slope of the charge versus energy curves on the $\log -\log$ plot $\left(S_{n}\right)$ yields the order $n$ of the $n$-photon process but gives limited information about the value of $\phi$ of a given sample (see Table IV). The reflectivity of the films could not be measured, since the surface roughness of the samples scattered the reflected light. The reflection and transmission coefficients of the (110) TypeIIa natural diamond was measured (Table VI).

Two samples were analyzed during one set of measurements. The electron yields of the copper sample holder were recorded during each set of measurements. This procedure would take into account the eventual laser pulsewidth or spot shape variation arising from day to day and ensured the reproducibility of the measurements. The values of $S_{1}$ and $b_{1}$ obtained from the copper mount were found to be very 
TABLE VI

Measured Reflection and Transmission Coefficients at Normal Incidence of the (110) Type Ila Natural Diamond

\begin{tabular}{|c|c|c|c|}
\hline & $\begin{array}{c}h v=5.73 \mathrm{eV} \\
\lambda=217 \mathrm{~nm}\end{array}$ & $\begin{array}{c}h v=3.82 \mathrm{eV} \\
\lambda=325 \mathrm{~nm}\end{array}$ & $\begin{array}{c}h v=1.91 \mathrm{eV} \\
\lambda=650 \mathrm{~nm}\end{array}$ \\
\hline$R$ & 0.23 & 0.23 & 0.27 \\
\hline$T$ & 0.00 & 0.79 & 0.72 \\
\hline
\end{tabular}

TABLE VII

Measured Slopes $S_{\eta}$ and Electron Yields $b_{n}$ with the Various Pure and Doped Diamond Films. The Values Obtained with a $(110)$ and a (111) Type IIa Diamond Monocrystal Are Also Grven

\begin{tabular}{|c|c|c|c|c|c|c|}
\hline \multirow[b]{2}{*}{ Sample } & \multicolumn{2}{|c|}{$h v=5.73 \mathrm{eV}$} & \multicolumn{2}{|c|}{$h v=3.82 \mathrm{eV}$} & \multicolumn{2}{|c|}{$h v=1.91 \mathrm{eV}$} \\
\hline & $S_{l}$ & $\begin{array}{c}b_{1} \\
{\left[p C \mu V^{t}\right]} \\
\end{array}$ & $S_{2}$ & $\begin{array}{c}b_{2} \cdot 10^{3} \\
{\left[p C \mu \gamma^{-2}\right]} \\
\end{array}$ & $S_{3}$ & $\begin{array}{r}b_{3} \cdot 10^{6} \\
{\left[p C \mu I^{3}\right]} \\
\end{array}$ \\
\hline Cauliflower & 1.03 & 5.12 & 2.22 & 1.86 & 3.12 & $1.3 \cdot 10^{-2}$ \\
\hline Well oriented & 0.97 & 3.54 & 1.88 & 3.02 & 3.33 & 550 \\
\hline$B$-doped & 1.04 & 45.7 & 1.99 & 10.2 & 3.42 & $2.0 \cdot 10^{-2}$ \\
\hline (110) type IIa & 0.98 & 3.04 & 1.91 & 2.69 & 2.62 & $1.3 \cdot 10^{-2}$ \\
\hline (111) type IIa & 0.97 & 4.18 & 1.85 & 6.36 & 2.43 & $2.5 \cdot 10^{-1}$ \\
\hline
\end{tabular}

consistent from day to day $(1.01 \pm 0.03$ and $275 \pm 25 \mathrm{pC}$ $\mu \mathbf{J}^{-1}$, respectively), because for a one-photon process [see (2) and (6)] the total charge is independent of the laser pulsewidth or spot area and only linearly dependent on eventual changes in the surface reflectivity $(R(h \nu=5.73 \mathrm{eV})=0.39$ at normal incidence, for a clean copper surface). Variations of $S_{2}$ and $b_{2}$ were only slightly larger $\left(2.03 \pm 0.05\right.$, and $(261 \pm 35) \cdot 10^{-3}$ $\mathrm{pC} \mu \mathrm{J}^{-2}$, respectively), even though the electron yield for this two-photon process depends linearly on the laser pulsewidth and spot area and quadratically with the surface reflectivity ( $R(h \nu=3.82 \mathrm{eV})=0.37$ at normal incidence). Variations of $S_{3}$ and $b_{3}$ were significantly larger $(3.0 \pm 0.15$, and (392 士 192) $\cdot 10^{-6} \mathrm{pC} \mu \mathbf{J}^{-3}$, respectively), probably resulting from the strong dependency of the three-photon electron yield on small pulsewidth, spot area, and surface reflectivity changes $(R(h \nu=1.91 \mathrm{eV})=0.943$ at normal incidence). Changes of reflectivity could arise from exposing the holder to atmosphere during a sample change or from hitting the mount at a slightly different spot from day to day. Note that the $b_{n}$ values obtained with the copper sample holder are slightly larger from the ones obtained with the mirror polished copper sample. The sample holder had only a machine finished surface and probably suffered from surface oxidation that could have lead to lower reflection coefficients. The samples studied in this experiment were characterized by the measured values of $S_{n}$ and $b_{n}$ at the above-mentioned wavelengths. The value of $b_{n}$ obtained from the power fit of the experimental data depends on the value of $n(6)$ or $S_{n}$ used. The $b_{n}$ 's given in this paper are the ones obtained with the actual values of $S_{n}$, but the units of the $b_{n}$ 's will be given in terms of the expected integer values of $n$ (and not in terms of $S_{n}$ ).

1) Silicon Substrates: The electron yields of various silicon samples used as substrates for the diamond and fullerene

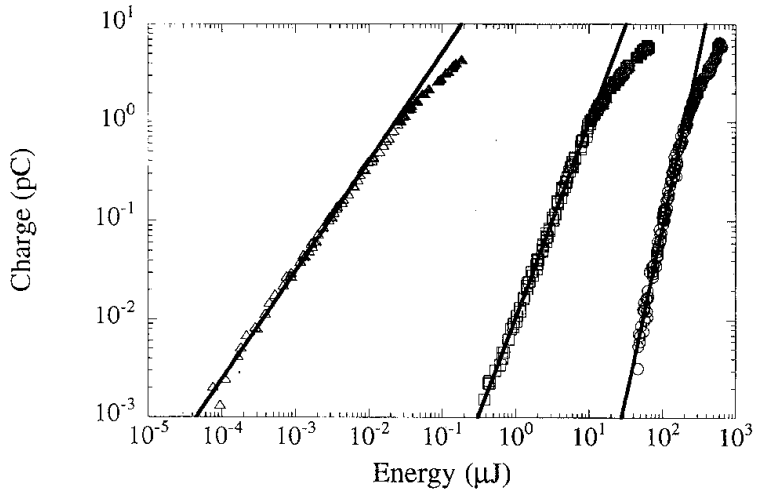

Fig. 5. Electron charge emitted by the boron-doped diamond film illuminated at normal incidence. The measured slopes $S_{n}$ ( $n$-photon order) and the corresponding $b_{n}$ 's from (6), obtained through power fits (straight lines) below the space-charge regime $(Q<1 \mathrm{pC}$, open symbols), are given in Table VII for the three wavelengths; circles: $h \nu=1.91$; squares: $h \nu=3.82$; triangles: $h \nu=5.73 \mathrm{eV}$. At higher charge values $(Q>1 \mathrm{pC}$, filled symbols $)$, the electron emission becomes space-charge limited.

films were measured to obtain an upper boundary for their contribution to the electron yield that could arise from their possible interstitial exposition to the incident light. The electron yields of a boron, $p$-doped (100) silicon substrate $(r=$ $11.0-25.0 \Omega \mathrm{cm}$, doping $\left.\approx 10^{15} \mathrm{~cm}^{-3}\right)$ and of a phosphorous, $n$-doped silicon substrate $\left(r=0.2-0.8 \Omega \mathrm{cm}\right.$, doping $\approx 10^{16}$ $\mathrm{cm}^{-3}$ ) are given in Table V. The values of $S_{1}$ and $S_{2}$ clearly indicate a one- and two-photon process at $217 \mathrm{~nm}$ and $325 \mathrm{~nm}$, respectively, showing that the work function of the samples is between 3.82 and $5.73 \mathrm{eV}$ (Table IV). This value is consistent with the value $\phi=5.15 \pm 0.08 \mathrm{eV}$ for intrinsic (111) Si measured in another experiment [38]. In that same experiment, the value of $\phi$ has been observed to decrease to about 4.8 $\mathrm{eV}$ for heavily $p$ - or $n$-doped samples $\left(\approx 10^{20} \mathrm{~cm}^{-3}\right)$. The $b_{n}$ values are of the order of $1 \%$ of the one measured with copper (Table III).

2) Diamond Samples: The electron yields of cauliflower and well-oriented pure diamond films and of boron-, $p$-doped $\left(r=4.3 \cdot 10^{-2} \Omega \mathrm{cm}\right.$, doping $\left.8 \cdot 10^{19} \mathrm{~cm}^{-3}\right)$ diamond film are shown in Table VII. As with the silicon substrates, the $S_{n}$ values at 217 and $325 \mathrm{~nm}$ clearly indicate one- and two-photon effects with all the samples. The values of $S_{3}$ are inconsistent with the $S_{1}$ and $S_{2}$ values. The boron-doped sample (Fig. 5) exhibits a significantly higher electron yield than all the other samples at UV wavelengths. Its $b_{1}$ value is almost 10 times larger than the undoped sample $b_{1}$ and reaches $20 \%$ of the copper mirror $b_{1}$. Its $b_{2}$ value is about five times larger than the undoped sample $S_{2}$ and reaches about $5 \%$ of the copper mirror $b_{2}$. Its electron yield at $650 \mathrm{~nm}$ is very small and does not exhibit the expected three-photon characteristic.

Electron yields were obtained from the (110) face of a 4.0 $\times 4.0 \times 0.25 \mathrm{~mm}^{3}$ and from the (111) face of a $3.0 \times 3.0 \times$ $0.25 \mathrm{~mm}^{3}$ Type IIa natural diamond. An $f=500 \mathrm{~mm}$ lens was used to fit the laser beam spot onto the diamond surface. The actual spotsizes at 325 and $650 \mathrm{~nm}$ were deduced from the comparison of the electron yields of the copper mount with the two spotsizes. The yields (325 and $650 \mathrm{~nm}$ ) presented in Table VII were scaled to the spotsize without a lens. The 
TABLE VIII

Measured Slopes $S_{n}$ AND Electron Yields $b_{n}$ WITH THE Pure Fullerene and the Argon-Treated Fullerene Sample

\begin{tabular}{|c|c|c|c|c|c|c|}
\hline \multirow[b]{2}{*}{ Sample } & \multicolumn{2}{|c|}{$h v=5.73 \mathrm{eV}$} & \multicolumn{2}{|c|}{$h v=3.82 \mathrm{eV}$} & \multicolumn{2}{|c|}{$h v=1.91 \mathrm{eV}$} \\
\hline & $S_{1}$ & $\begin{array}{c}b_{1} \\
{\left[p C \mu J^{\prime}\right]} \\
\end{array}$ & $S_{2}$ & $\begin{array}{c}b_{2} \cdot 10^{\top} \\
{\left[p C \mu J^{2}\right]} \\
\end{array}$ & $S_{3}$ & $\begin{array}{c}b_{3} \cdot 10^{6} \\
{\left[p C \mu J^{-3}\right]} \\
\end{array}$ \\
\hline Pure fullerene & 1.06 & 1.35 & 1.9 .4 & 2.94 & - & - \\
\hline Arfullerene & 0.98 & 0.62 & 1.96 & 0.83 & - & - \\
\hline
\end{tabular}

electron yields of the natural diamonds and of the cauliflower and well-oriented thin film obtained with UV light are similar. The measured slopes are consistent with the work function value of $5.5 \mathrm{eV}$ obtained previously for pure diamond [6] and approximately $6.0 \mathrm{eV}$ for blue diamond [39]. Note that the laser pulses are incident on the (111) surface of three of the six samples: the well-oriented, the $B$-doped, and the (111) natural diamond.

The reflection and transmission coefficient of the (110) Type Ila natural diamond for normal incidence light at the three frequencies available for this experiment were measured using the actual laser pulses. The results are shown in Table VI, the error on $R$, and $T$ is \pm 0.05 . Pure diamond showed no significant absorption of the 3.82 and $1.91 \mathrm{eV}$ photons but absorbed about $77 \%$ of the incident $5.73 \mathrm{eV}$ photons.

Photoemission from a heavily boron-doped diamond film $(1-10 \Omega \mathrm{cm})$ deposited on molybdenum has been reported by Fisher et al. [40]. $S_{n}$ values of 1 and approximately 3 were observed with 5 and $2 \mathrm{eV}$ photons, respectively. The electron yield of the diamond film with $2 \mathrm{eV}$ photons was comparable to the yield of a magnesium sample illuminated at $75^{\circ}$. The QE measured with $5 \mathrm{eV}$ photons was $6 \cdot 10^{-6}$.

3) Fullerene Samples: The clectron yields of a pure fullerene and an argon treated pure fullerene sample are shown in Table VIII. The electron yields at the UV wavelength were small for all the samples, around $1 \%$ of the copper values, and the data at $650 \mathrm{~nm}$ showed no consistent behavior. The optical absorbance of fullerene [41] is low for photons with energies below the bandgap energy $(2.3-1.6 \mathrm{eV}$, or $540-770 \mathrm{~nm})$. The absorbance increases to about one for photons with energies above the bandgap energy $(6.2-2.3 \mathrm{eV}$, or $200-540 \mathrm{~nm})$. The measured slopes $\left(b_{1}\right.$ and $\left.b_{2}\right)$ indicate a one-photon process at $217 \mathrm{~nm}$ and a two-photon process at $325 \mathrm{~nm}$ with both samples, i.e., $3.82<\phi<5.73 \mathrm{eV}$ which is inconsistent with the previously measured $\mathrm{C}_{60}$ work function of $6.8 \mathrm{eV}$ [17].

\section{DAMAge MeASUREMENT}

For the photoemission processes, the energy of the incident laser pulse was kept low enough so that only electrons (no ions) were produced at the photoemitter surface. Optical damage occurs when the power (long pulse) or the fluence (short pulse) of the laser pulse [42] is large enough to change the configuration of the surface. Melting of the surface and extraction of ions or ablation, i.e., the creation of a surface plasma, are the two main damage processes. In the electron photoemission experiment the photocathode is grounded, and the anode is biased at a positive potential; optical damage manifested itself through a sudden increase of the emitted electron charge and/or a strong and random dependency of the observed charge versus the incident energy. The cathode-anode bias voltage polarity was reversed (anode biased at a negative potential) to observe the ion current generated by the laser pulse incident on the photocathode. The nature of the emitted ions was not determined. The onset of ion current was then used as a measure of the damage threshold (DT). In the case of a mirror polished copper photocathode, low level damage was observed to create a cloudiness or a white halo on the surface. Severe damage resulted in the creation of pits and craters on the surface.

Fig. 6 shows the electron and ion charges emitted by the machine finish copper holder, the (110) Type IIa natural diamond, and the boron-doped film illuminated by $1.91 \mathrm{eV}$ laser pulses focused to $2.7 \cdot 10^{-3} \mathrm{~cm}^{2}$. The anode bias voltage was kept low $(+2$ or $-2 \mathrm{kV})$ to limit the risk of electrical breakdown between the anode and the cathode. Consequently, most of the electron charge was emitted in the space-charge limited regime, and the three-photon character of the electron charge curves is not apparent in these figures. The measurements were started from the low energy side of the curves to observe the charge emitted before and after the surface was damaged. The electron and ion charges are represented as positive on these figures. In this experiment the minimum measurable charge is $1 \cdot 10^{-3}$ pC. From Fig. 6(a)-(c), a threshold value for the onset of positive charge or ion emission can be deduced because of the large observed slope of the charge versus laser energy. The observed energy thresholds are 10, 20, and $250 \mu \mathrm{J}$ for the copper, boron-doped diamond film, and natural diamond, respectively, corresponding to fluences of

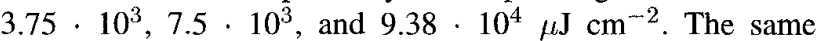
measurements were performed at 325 and $217 \mathrm{~nm}$. At 325 $\mathrm{nm}$, the observed threshold fluences were $3.3 \cdot 10^{2}, 5 \cdot 10^{2}$, and $1.2 \cdot 10^{3} \mu \mathrm{J} \mathrm{cm}^{-2}$, respectively. The energy threshold was found to increase linearly with the decreasing spotsize, all other parameters kept constant. At $217 \mathrm{~nm}$, positive charge emission was observed at all energies used (i.e., $>1 \mu \mathrm{J}$ ) with all the samples and with a yield about 20 times smaller than the electron yield. The ion emission probably resulted from ablation of surface hydrocarbon contaminants rather than from damage to the material itself. With all samples, the onset of positive charge emission was usually accompanied by an increase of the emitted electron charge at a slightly higher energy, as can be seen in Fig. 6(a) and (c). This increase could result from the diminution of the space-charge effect caused by the presence of the emitted ions confined to the sample surface by the applied electric field.

\section{SUMMARY AND DISCUSSION}

The slopes obtained with UV light $\left(S_{1}\right.$ at $217 \mathrm{~nm}$ and $S_{2}$ at $325 \mathrm{~nm}$ ) consistently reflected the quantum nature of the single electron emission photoemission processes. The measured slopes were within $\pm 10 \%$ of the integer values, indicating that the work function of the samples are between 3.82 and $5.73 \mathrm{eV}$, in agreement with the published values [6], 


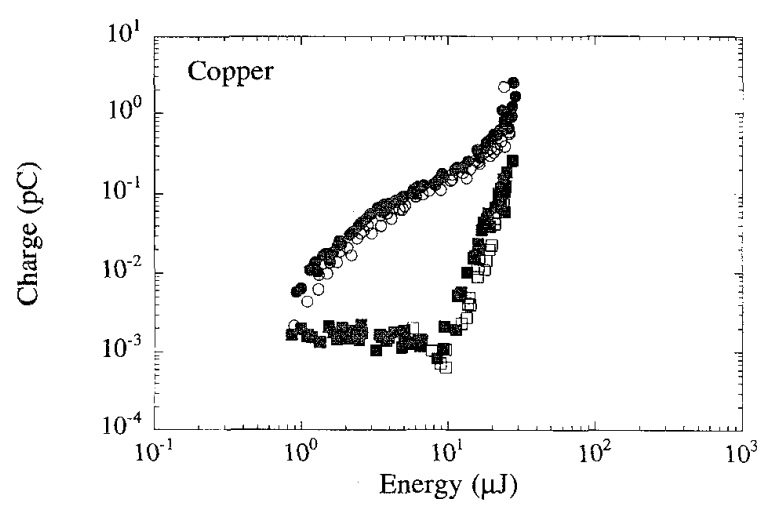

(a)

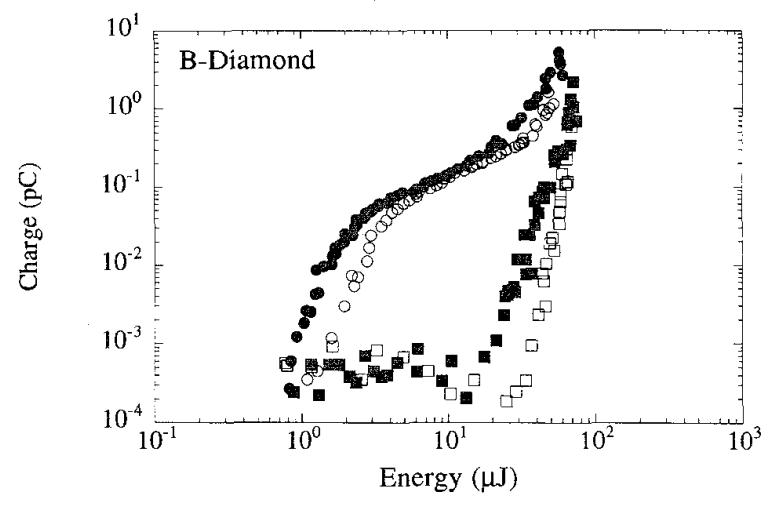

(b)

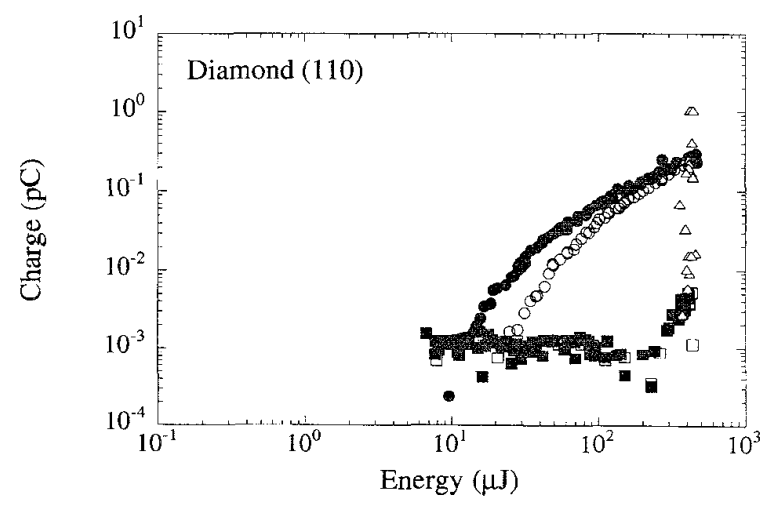

(c)

Fig. 6. Electron and ion charge emitted by (a) the machine finish copper holder, (b) the boron-doped diamond film, and (c) the (110) natural Type IIa diamond illuminated by the $1.91 \mathrm{eV}$ photon laser pulse focused to $2.7 \cdot 10^{-3}$ $\mathrm{cm}^{2}$ (fluence $3.7 \cdot 10^{3} \mathrm{~J} \mathrm{~cm}^{-2}$, intensity $5.3 \cdot 10^{15} \mathrm{~W} \mathrm{~cm}^{-2}$ at $10 \mu \mathrm{J}$ ). The circles represent the electron charge emitted when the anode was biased with a positive voltage $(+2 \mathrm{kV})$. The squares represent the ion charge emitted when the anode was biased with a negative voltage $(-2 \mathrm{kV})$. The triangles in (c) represent the equivalent of an electron charge emitted with a negatively biased voltage. The filled symbols represent the charge obtained before reaching the damage threshold, and the empty symbols represent the charge obtained after reaching the damage threshold.

[38] except for the fullerene samples [17]. It is not understood why some of the yields observed with the $1.91 \mathrm{eV}$ photons did not always yield slopes consistent with the ones observed with UV photons, or even with any $n$-photon process.

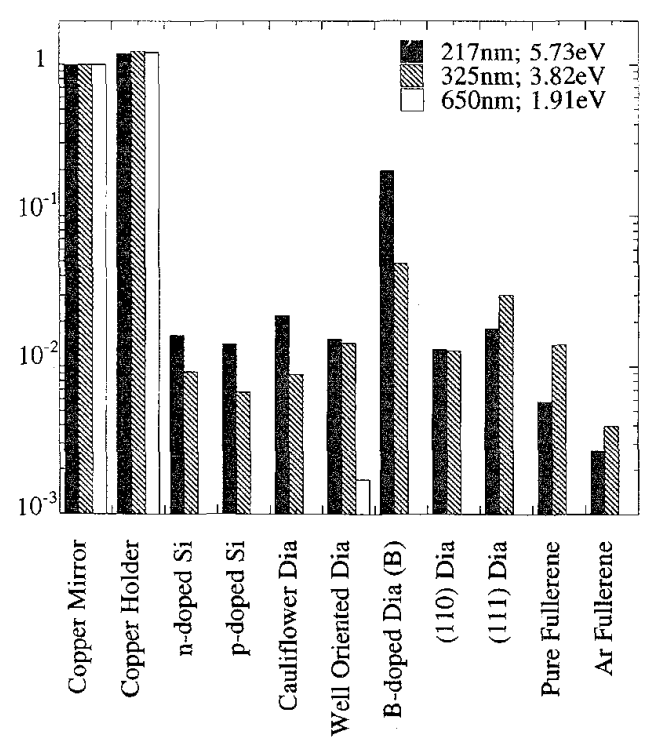

Fig. 7. Summary of the electron yields of all the samples. The $b_{n}$ 's (given in Tables III, V, VII, and VIII) for each sample are normalized to the $b_{n}$ 's of the copper mitror. The QE of the copper mirror (at $217 \mathrm{~nm}$ ) was $1.3 \cdot 10^{-3}$, corresponding to the normalized electron yield of 1.0.

All the samples studied in this experiment showed electron yields of the order of $1 \%$ or less of the electron yields of copper (see Fig. 7), except for the boron-, p-type diamond film illuminated with UV light. Although this sample exhibited a very low electron yield with the $1.91 \mathrm{eV}$ photons, the yields with the 3.82 and $5.73 \mathrm{eV}$ photons reached $5 \%$ and $20 \%$ of the respective copper yields. The QE of the boron-doped film is $2.62 \cdot 10^{-4}$ at $217 \mathrm{~nm}$ without any significant Schottky effect. This $\mathrm{QE}$ is nine times larger than the $\mathrm{QE}$ of the pure diamond samples (Table VII), including the predominately (111) well-oriented film and the (111) diamond monocrystal. The coarse measurement of the reflection and absorption coefficients of the (110) natural diamond sample showed that the 1.91 and $3.82 \mathrm{eV}$ photons are not significantly absorbed by diamond. Diamond is an indirect bandgap semiconductor and weak optical absorption is expected below $7.3 \mathrm{eV}$ (the lowest energy direct transition), leading to low electron yields at wavelengths longer than $180 \mathrm{~nm}$ (diamond is transparent to visible light). Even though the $0.25 \mathrm{~mm}$ thick diamond absorbed about $77 \%$ of the incident $5.73 \mathrm{eV}$ photons (Table VI), its electron yield was small. The doping of diamond could enhance its electron yield through three effects: 1) an increase of the optical absorption (at a given wavelength) caused by the presence of the doping impurity, 2) a decrease of the surface electron affinity cause by the creation of surface states, and 3) an increase of the conduction band population or an increase of the Fermi level energy (for $p$-type doping). Each of the three effects may have contributed to the enhancement of the boron-, $p$-doped UV electron yields. The two fullerene thin films exhibited low electron yields, indicating that pure fullerene is not a suitable material as photoemitter.

The fluence threshold for ion emission, i.e., damage, observed with the natural diamond illuminated by the $1.91 \mathrm{eV}$ photon pulse was $9.38 \cdot 10^{4} \mu \mathrm{J} \mathrm{cm}^{-2}$, i.e., 25 times larger 
than the threshold observed with copper. The same threshold for the boron-doped diamond film, which exhibited the highest electron yields with UV light, was two times larger than the threshold for copper. The thresholds observed with the $325 \mathrm{~nm}$ UV light were lower and comparable for each sample $(<1.2$. $10^{3} \mu \mathrm{J} \mathrm{cm}^{-2}$ ). All the samples exhibited ion emission at 217 $\mathrm{nm}$ incident light even with the lowest fluence $\left(2.5 \cdot 10^{-3} \mu \mathrm{J}\right.$ $\mathrm{cm}^{-2}$ ). Further experiments are currently being performed to determine the nature of the ion emission and its relation to surface damage. The literature on laser-induced damage of materials is abundant, but the comparison between the published results on laser-induced DT remains difficult because of the variety of laser parameters (wavelength, pulsewidth, single or multiple shots), of diagnostics (ion emission, plasma formation, reflection-transmission alteration, visible damage), and of the surfaces condition or preparation. The damage threshold fluence at a given wavelength and for a given material scales as $\sigma_{t}^{1 / 2}$ for laser pulse longer than $\sigma_{t}=$ $10 \mathrm{ps}$ [43]. The threshold for ion emission observed in this experiment with a Type IIa diamond $\left(1.34 \cdot 10^{11} \mathrm{~W} \mathrm{~cm}^{-2}\right.$, with $700 \mathrm{fs}-650 \mathrm{~nm}$ pulses) compares to the threshold for surface melting $\left(6 \cdot 10^{12} \mathrm{~W} \mathrm{~cm}^{-2}\right.$, with $90 \mathrm{fs}-620 \mathrm{~nm}$ pulses) obtained by observing the changes in surface reflection and transmission of the sample [44]. The DT obtained with the copper sample $\left(5.35 \cdot 10^{9} \mathrm{~W} \mathrm{~cm}{ }^{-2}\right.$, with $700 \mathrm{fs}-650 \mathrm{~nm}$ pulses) is higher than the thresholds observed with a (100) copper surface under ultra-high vacuum $\left(6 \cdot 10^{7} \mathrm{MW} \mathrm{cm}^{-2}\right.$ for ion emission, and $3 \cdot 10^{8} \mathrm{MW} \mathrm{cm} \mathrm{cm}^{-2}$ for visible damage with $12 \mathrm{~ns}-590 \mathrm{~nm}$ pulses [45]). The PECT diamond film used in this experiment was not polished, and possible inclusion of graphite in the films may increase their absorption and thus the observed DT. The copper samples were exposed to air and kept under a modest vacuum $\left(10^{-7} \leq P \leq 10^{-6}\right.$ torr $)$. The DT's obtained in this experiment are thus more representative of these particular samples than of the intrinsic properties of diamond and copper. Nevertheless, the compilation of the published diamond DT's [46] shows that high-quality polished CVD diamond films exhibit DT's only 15 to $20 \%$ lower than these of single crystal diamond. Using published values for DT's ( $>2 \cdot 10^{8} \mathrm{~W} \mathrm{~cm}^{-2}$ for single crystal diamond with 193 $\mathrm{nm}, 15 \mathrm{~ns}$ pulses [47], and $10^{9} \mathrm{~W} \mathrm{~cm}^{-2}$ for copper and $266 \mathrm{~nm}-\leq 12 \mathrm{ps}$ pulses [48]) and the QE's obtained in this experiment with $217 \mathrm{~nm}$ light for the boron-doped diamond film and with $266 \mathrm{~nm}$ light for the mirror polished copper, one can conclude that the product (QE.DT) for diamond films (2.6 $\cdot 10^{-4} \cdot 0.8 \cdot 8.5 \cdot 10^{-2} \mathrm{~J} \mathrm{~cm}^{-2} \cdot(12 \mathrm{ps} / 15 \mathrm{~ns})^{1 / 2}=5.0 \cdot 10^{-7}$ $\left.\mathrm{J} \mathrm{cm}^{-2}\right)$ and copper $\left(1 \cdot 10^{-5} \cdot 1.2 \cdot 10^{-2} \mathrm{~J} \mathrm{~cm}^{-2}=1.2 \cdot 10^{-7}\right.$ $\mathrm{J} \mathrm{cm}^{-2}$ ) are comparable for picosecond pulses.

The results presented in this paper show that the borondoped diamond film (doping $6 \cdot 10^{19}-3 \cdot 10^{20} \mathrm{~cm}^{-3}$ ) has a one-photon electron yield comparable to that of copper at $217 \mathrm{~nm}$ and much larger than that of a natural single crystal diamond. Increasing the doping concentration (while preserving the diamond crystalline structure) to increase the electron yield of the diamond film and improving the film quality (uniformity, roughness, graphite content) to increase the damage threshold of the surface could make diamond a suitable photoemitter material for RF guns. The region of the RF cavity illuminated by the UV laser pulse could be coated with a submicron film of $p$-doped diamond and could become insensitive to exposure to air or to other vacuum contaminants. The behavior of the diamond film in the high amplitude RF field environment, as well as the effect of the presence of a semiconducting layer in the RF cavity, remain to be studied. With its large work function, diamond requires a laser wavelength shorter than $225 \mathrm{~nm}$ to generate a one-photon process necessary for the RF gun stability. Conversely, by using a high-order multiphoton process, electron pulses shorter in duration than the laser pulse could be obtained, in principle, using a diamond cathode which can tolerate a high photon flux before damage [34].

\section{REFERENCES}

[1] S. C. Hartman, N. Barov, C. Pellegrini, S. Park, J. Rosenzweig, G. Travish, R. Zhang, C. Clayton, P. Davis, M. Everret, C. Joshi, and G. Harapetian, "Initial measurement of the UCLA RF photoinjector," Nucl. Instr. Meth., vol. A340, pp. 219-230, 1994.

[2] X. J. Wang, T. Srinivasan-Rao, K. Batchelor, I. BenZvi, and J. Fisher, "Measurements on photoelectrons from a magnesium cathode in a microwave electron gun," Nucl. Instr. Meth., vol. A356, pp. 159-166, 1995.

[3] E. Chevallay, J. Durand, S. Hutchins, G. Suberlucq, and M. Wurgel, "Photocathodes tested in the dc gun of the CERN photoemission laboratory," Nucl. Instr. Meth., vol. A340, pp. 146-156, 1994.

[4] S. C. Chen, J. Gonichon, L. C. L. Lin, R. J. Temkin, S. Trotz, B. G. Danly, and J. S. Wurtele, "High gradient acceleration in a $17 \mathrm{GHz}$ photocathode RF gun," in Proc. IEEE Particle Accelerator Conf., 1993, pp. 2575-2577.

[5] J. van der Weide and R. J. Nemanich, "Argon and hydrogen plasma interaction on diamond (111) surfaces: Electronic states and structure," Appl. Phys. Lett., vol. 62, no. 16, pp. 1878-1880, 1993.

[6] F. J. Himpsel, J. A. Knapp, J. A. VanVechten, and D. E. Eastman, "Quantum photoyield of diamond (111)--A stable negative affinity emitter," Phys. Rev., vol. B20, no. 2, pp. 624-627, 1979.

[7] M. W. Geis, N. N. Efremow, J. D. Woodhouse, M. D. McAleese, M. Marchywka, D. G. Socker, and J. F. Hochedez, "Diamond cold cathode," IEEE Elect. Dev. Lett., vol. 12, no. 8, pp. 456-459, 1991.

[8] C. Wang, A. Garcia, D. C. Ingram, M. Lake, and M. E. Kordesh, "Cold field emission from CVD diamond films observed in emission electron microscopy," Electron. Lett., vol. 27, no. 16, pp. 1459-1461, 1991.

[9] G. L. Pearson and J. Bardeen, "Electrical properties of pure silicon and silicon alloys containing boron and phosphorus," Phys. Rev., vol. 75, pp. 865-883, 1949.

[10] M. N. Yoder, "Diamond: Its impact on electronics," Naval Res. Rev., vol. 44, no. 3, pp. 17-21, 1992 .

[11] R. M. Chrenko, "Boron, the dominant acceptor in semiconducting diamond," Phys. Rev., vol. B7, pp. 4560-4567, 1973.

[12] F. G. Celii, A. J. Purdes, B. E. Gnade, and D. L. Weathers, "New diamond science and technology," in Proc. 2nd Int. Conf. New Diamond Sci. Technol., R. Messier and J. T. Glass, Eds., 1991, pp. 631-636.

[13] H. W. Kroto, J. R. Heath, S. C. O'Brien, R. F. Curl, and R. E. Smalley, "C 60 : Buckminsterfullerene," Nature, vol. 318, pp. 162-163, 1985.

[14] W. Krãtschmer, L. D. Lamb, K. Fostiropoulos, and D. R. Huffman, "Solid $\mathrm{C}_{60}$ : A new form of carbon," Nature, vol. 347, pp. 354-358, 1990.

[15] R. E. Haufler, L.-S. Wang, L. P. F. Chibante, C. Jin, J. Conceicao, Y. Chai, and R. E. Smalley, "Fullerene triplet state production and decay: R2PI probes of $\mathrm{C}_{60}$ and in a supersonic beam," Chem. Phys. Lett., vol. 179 , pp. $449-453,1991$.

[16] D. L. Lichtenburger, K. W. Nebesny, C. D. Ray, D. R. Huffman, and D. Lamb, "Valence and core photoelectron spectroscopy of $\mathrm{C}_{60}$, buckminsterfullerene," Chem. Phys. Lett., vol. 176, pp. 203-208, 1991.

[17] G. K. Wertheim, J. E. Rowe, D. N. Buchanan, E. E. Chaban, A. F. Hebard, A. R. Kortan, A. V. Makhija, and R. C. Haddon, "Photoemission spectra and electronic properties of $\mathbb{K}_{x} \mathrm{C}_{60}, " S c i$, vol. 252 , pp. 1419-1421, 1991.

[18] R. C. Hadon, A. F. Hebard, M. J. Rosseinsky, D. W. Murphy, S. J. Duclos, K. B. Lyons, B. Miller, J. M. Rosamilia, R. M. Fleming, A. R. Kortan, S. H. Glarum, A. V. Makhija, A. J. Muller, R. H. Eick, S. M. Zahurak, R. Tycko, G. Dabbagh, and F. A. Thiel, "Conducting films of 
$\mathrm{C}_{60}$ and $\mathrm{C}_{70}$ by alkali metal doping," Nature, vol. 350 , pp. 320-322, 1990.

[19] A. F. Hebard, M. J. Rosseinsky, R. C. Hadon, D. W. Murphy, S. H. Glarum, T. T. M. Palstra, A. P. Ramirez, and A. R. Kortan, "Superconductivity at $18 \mathrm{~K}$ in potassium-doped $\mathrm{C}_{60}, "$ Nature, vol. 350 , pp. 600-601, 1990.

[20] R. A. Milikan, "A direct photoelectric determination of Planck's $h$," Phys. Rev., vol. 7, pp. 355-388, 1916.

[21] E. M. Logothetis and P. L. Hartman, "Laser induced emission from solids: Many-photon photoelectric effects and thermionic emission," Phys. Rev., vol. 187, no. 2, pp. 460-474, 1969.

[22] P. L. Bechtel, W. L. Smith, and N. Bloembergen, "Two-photon photoemission from metals induced by picosecond laser pulses," Phys. Rev. B, vol. 15 , no. 10, pp. 4557-4563, 1977.

[23] T. Maruyama, E. L. Garwin, R. A. Mair, R. Prepost, J. S. Smith, and J. D. Walker, "Electron-spin polarization in photoemission from thin $\mathrm{Al}_{x} \mathrm{Ga}_{1-x} \mathrm{As}, "$ J. Appl. Phys., vol. 73, no. 10, pp. 5189-5192, 1993.

[24] W. J. Siekhaus, J. H. Kinney, D. Milam, and L. L Chase, "Electron emission from insulator and semiconductor surfaces by multiphoton excitation below the damage threshold," Appl. Phys. A, vol. 39, no. 3, pp. $163-166,1986$.

[25] R. H. Fowler, "The analysis of photoelectric sensitivity curves for clean metals at various temperatures," Phys. Rev., vol. 38, pp. 45-56, 1931.

[26] L. E. DuBridge, "Theory of the energy distribution of photoelectrons," Phys. Rev., vol. 43, pp. 727-741, 1933.

[27] R. L. Bell, Negative Electron Affinity. Oxford, U.K.: Clarendon, 1973, pp. $61-63$.

[28] S. M. Sze, J. L. Moll, and T. Sugano, "Range-energy relation of hot electrons in gold," in Solid-State Electronics, vol. 7. New York: Pergamon, 1964, pp. 509-523.

[29] S. Matsumoto, Y. Sato, M. Tsutsumi, and N. Setaka, "Growth of diamond particles from methane-hydrogen gas," J. Mater. Sci., vol. 17, pp. 3106-3112, 1982.

[30] M. Kamo, Y. Sato, S. Matsumoto, and N. Setaka, "Diamond synthesis from gas phase in microwave plasma," $J$. Crystal Growth, vol. 62, pp. $642-644,1983$

[31] F. Akatsuka, Y. Hirose, and K. Komaki, "Rapid growth of diamond films by arc discharge plasma CVD," Jpn. J. Appl. Phys, vol. 27, no. 9, pp. L1600-L1602, 1988

[32] S. Jou, H. J. Doerr, and R. F. Bunshah, "Diamond coatings from a solid carbon source," Thin Solid Films, vol. 253, pp. 95-102, 1994.

[33] W. Schottky, "Uber kalte und warme Electronementladungen," W. Z. Phys., vol. 14, pp. 63-106, 1923.

[34] R. Brogle, P. Muggli, and C. Joshi, "Studies of linear and nonlinear photoemission for advance accelerator application," Bullet. Amer. Phys. Soc., vol. 40 , no. 3, p. $1172,1995$.

[35] T. Anderson, I. V. Tomov, and P. Rentzepis, "Laser-driven metal photocathodes for picosecond electron X-ray pulse generation," J. Appl. Phys., vol. 71, no. 10, pp. 5161-5167, 1992.

[36] T. Srinivasan-Rao, J. Fisher, and T. Tsang, "Photoemission studies on metals using picosecond ultraviolet laser pulses," J. Appl. Phys., vol. 69 , no. 5, pp. 3291-3296, 1991

[37] W. F. Krolikowski and W. E. Spicer, "Photoemission studies of the noble metals - I copper," Phys. Rev., vol. 185, pp. 882-900, 1969.

[38] F. G. Allen and G. W. Gobeli, "Work function, photoelectric threshold, and surface states of atomically clean silicon," Phys. Rev., vol. 127, no. 1 , pp. $150-158,1962$

[39] W. F. Wei and W. J. Levino, "Photoelectric emission and work function of semiconducting diamond," Carbon, vol. 13, pp. 425-427, 1975.
[40] J. Fisher, T. Srinivasan-Rao, T. Tang, and G. Brandes, "Photoemission from magnesium and from diamond film using high intensity laser beams," Nucl. Instr. Meth. Phys. Res. A, vol. 340, pp. 190-194, 1994.

[41] A. Skumanich, "Optical absorption spectra of carbon 60 thin films from 0.4 to $6.2 \mathrm{eV}$," Chem. Phys. Lett., vol. 182, no. 5, pp. 486-490, 1991.

[42] P. B. Corkum, F. Brunel, N. K. Sherman, and T. Srinivasan-Rao, "Thermal response of metals to ultrashort-pulse laser excitation," Phys. Rev. Lett., vol. 61, no. 25, pp. 2886-2889, 1988.

[43] D. Du, X. Liu, G. Korn, J. Squier, and G. Mourou, "Laser induced breakdown by impact ionization in $\mathrm{SiO}_{2}$ with pulse widths from $7 \mathrm{~ns}$ to 150 fs," Appl. Phys. Lett., vol. 64, no. 23, pp. 3071-3073, 1994.

[44] D. Reitze, H. Ahn, X. Wang, and M. C. Downer, "Femtosecond melting of diamond," in Ultrafast Phenomena VII, C. Harris, E. Ippen, G. Morou, and A. Zewail, Eds. Berlin: Springer-Verlag, 1990, pp. 113-115.

[45] P. G. Strupp, P. C. Stair, and E. Weitz; "Pulsed laser-induced electron and positive ion emission from $\mathrm{Cu}(100)$ under ultrahigh-vacuum conditions near the threshold for surface damage," J. Appl. Phys., vol. 69, no. 6 , pp. $3472-3479,1991$.

[46] C. A. Klein, "Pulsed laser-induced damage to diamond," Diamond Films Technol, vol. 5, no. 3, pp. 141-158, 1995.

[47] T. R. Anthony, W. F. Banhozer, J. F. Fleisher, L. Wei, P. K. Kuo, R. L. Thomas, and R. W. Pryor, "Thermal diffusivity of isotopically enriched ${ }^{12}$ C diamond," Phys. Rev. B, vol. 42, no. 2, pp. 1104-1111, 1990.

[48] X. J. Wang, T. Tang, H. Kirk, T. Srinivasan-Rao, J. Fisher, K. Batchelor P. Russell, and R. C. Fernow, "Intense electron emission due to picosecond laser produced plasmas in high gradient electric fields," $J$. Appl. Phys, vol. 72, no. 1, pp. 888-894, 1992.

P. Muggli, photograph and biography not available at the time of publication.

R. Brogle, photograph and biography not available at the time of publication.

S. Jou, photograph and biography not available at the time of publication.

H. J. Doerr, photograph and biography not available at the time of publication.

R. F. Bunshah, photograph and biography not available at the time of publication.

C. Joshi (M'83-SM'88-F'93), photograph and biography not available at the time of publication. 